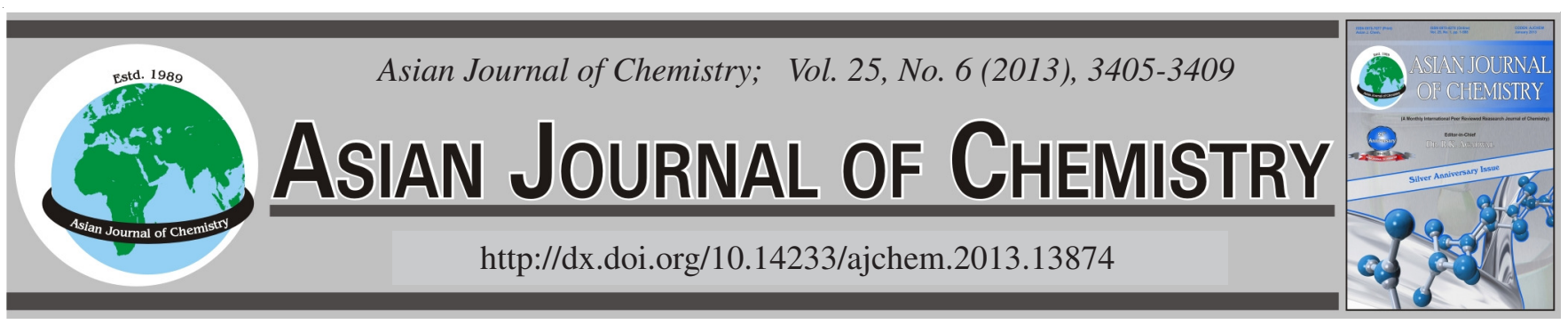

\title{
Synthesis and Characterization of Silver Oxide and Silver Chloride Nanoparticles with High Thermal Stability
}

\author{
M. Rafiq H. Siddiqü, S.F. Adil, M.E. Assal, Roushown Ali and A. Al-Warthan
}

Department of Chemistry, College of Science, King Saud University, P.O. 2455, Riyadh 11451, Kingdom of Saudi Arabia

*Corresponding author: E-mail: rafiqs@ksu.edu.sa

(Received: 10 April 2012;

Accepted: 24 December 2012)

AJC-12599

In present studies, the synthesis of nanoparticles of silver oxide and silver chloride were carried out. The silver oxide nanoparticles were |
synthesized employing capping method while silver chloride nanoparticles were synthesized by simple precipitation of silver nitrate
solution. Transmission Electron microscopic studies show that the size of silver oxide nanoparticles obtained is in the range of $2-10 \mathrm{~nm}$ while
the size of silver chloride nanoparticles was found to be in the range of $2-12 \mathrm{~nm}$. Silver chloride nanoparticles were found to be stable even
at $650{ }^{\circ} \mathrm{C}$. Thermal studies suggest that silver chloride nanoparticles behave like ionic liquid or molten salt in the range of $455-650{ }^{\circ} \mathrm{C}$.
Key Words: Synthesis, Nanoparticles, Silver chloride, Silver oxide, Electron microscopy.

\section{INTRODUCTION}

Nanoparticles have attracted considerable interest in isolated and in consolidated forms as they exhibit unique properties that differ significantly from their coarse-grained counterparts. Metal nanoparticles have many potential applications, including use in biomedical $^{1}$, optoelectronic ${ }^{2}$ and catalysis systems ${ }^{3}$ which relate to their size-dependent properties. Silver and its salts as nanoparticles are of particular interest owing to their potential applications in fuel cells ${ }^{4}$, heterogeneous catalysts ${ }^{5,6}$, coating of medical devices ${ }^{7}$, sterilization of sanitary napkins ${ }^{8}$, anti-tumour ${ }^{9}$ and antimicrobial chemotherapeutic agents ${ }^{10}$, etc. due to which various methods of synthesis of silver salts nanoparticles and their novel applications are constantly being explored. Silver oxide has been found to possess a variety application of which a few are light transmitting adhesive film ${ }^{11}$, as rechargeable cathode of secondary silver-zinc battery ${ }^{12}$, in synthesis of $\mathrm{Ag}_{5} \mathrm{~Pb}_{2} \mathrm{O}_{6}-\mathrm{Ag}$ ceramics $^{13}$, it has been used in form of paste for the manufacture of printed circuit board ${ }^{14}$, while silver chloride has been found to be applicable in measurements detecting $\mathrm{pH}$ change in microregion in activated sludge or biofilm for sewage treatment electrodes for $\mathrm{pH}^{15}$, as pressure-induced superconductors ${ }^{16}$, as catalyst for stereoselective cascade alkylation/cyclization of terminal alkynes with salicaldehydes when complexed with phosphines $^{17}$, for imparting antibacterial properties in textiles.

Owing to the importance of silver salts an attempt was made to synthesize silver nanoparticles. We herein report a facile synthesis of silver oxide nanoparticles and silver chloride nanoparticles.

\section{EXPERIMENTAL}

The metal salts used have been acquired from WINLAB chemicals Ltd. (U.K.) and were used without further purification. Oleic acid and sodium hydroxide and the solvents mentioned were obtained from BDH Chemicals (England). Scanning electron microscopy (SEM) and elemental analysis (Energy Dispersive X-Ray Analysis: EDX) were carried out using Jeol SEM model JSM 6360A, while transmission electron microscopy (TEM) was carried out using Jeol TEM model JEM-1101. Powder X-ray diffraction studies were carried out using a Altima IV [Make: Regaco] X-ray diffractometer, Fourier transform infrared spectroscopy (FT-IR) was carried out using a Perkin-Elmer 1000 FT-IR spectrophotometer and thermogravimetric analysis was carried out usinga PerkinElmer thermogravimetric analyzer ${ }^{7}$.

Silver chloride nanoparticles: To $200 \mathrm{~mL}$ silver nitrate 0.1 M solution, 0.5 M solution $\mathrm{HCl}$ was added until the precipitation of $\mathrm{AgCl}$ has seized. The greyish white precipitate obtained was filtered, washed with distilled water several times and then dried in an oven at $60{ }^{\circ} \mathrm{C}$ for 3-4 h till the $\mathrm{AgCl}$ is completely dry and powdery. The dried $\mathrm{AgCl}$ was calcined in a muffle furnace at $650{ }^{\circ} \mathrm{C}$ for $10 \mathrm{~h}$. The calcined sample was then allowed to cool down and stored in a dessicator. The resulting material was then characterized by scanning electron microscopy, together with elemental analysis using (energy dispersive X-ray analysis: EDX), transmission electron microscopy, powder X-ray diffraction techniques, Fourier transform infrared spectroscopy and thermogravimetric analysis. 
Silver oxide nanoparticles: Equimolar quantity of silver nitrate $4.61 \mathrm{~g}(0.0271 \mathrm{~mol})$ was reacted with $8.25 \mathrm{~g}$ $(0.0271 \mathrm{~mol})$ sodium oleate to yield silver oleate. The silver oleate thus obtained was added to triethylene glycol and heated to reflux temperature while stirring continuously for about $2 \mathrm{~h}$. The reaction mixture was then centrifuged for $10 \mathrm{~min}$ and the supernatant was discarded, the solid left at the bottom was then dispersed in hexane and stored as such. The product obtained was characterized by scanning electron microscopy, transmission electron microscopy and surface analysis (energy dispersive X-ray analysis: EDX), powder X-ray diffraction techniques, Fourier transform infrared spectroscopy and thermogravimetric analysis. A schematic representation is given in Fig. 1.

\section{$\left[\mathrm{CH}_{3}\left(\mathrm{CH}_{2}\right)_{7} \mathrm{CH}=\mathrm{CH}\left(\mathrm{CH}_{2}\right)_{7} \mathrm{COOH}\right]+\mathrm{NaOH}$} Oleic Acid

$$
\downarrow \mathrm{H}_{2} \mathrm{O}
$$

\section{$\left[\mathrm{CH}\left(\mathrm{CH}_{2}\right)_{7} \mathrm{CH}=\mathrm{CH}\left(\mathrm{CH}_{2}\right)_{7} \mathrm{COONa}\right]+\mathrm{AgNO}_{3}$}

Sodium Oleate

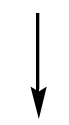

\section{$\left[\mathrm{CH}\left(\mathrm{CH}_{2}\right)_{7} \mathrm{CH}=\mathrm{CH}\left(\mathrm{CH}_{2}\right)_{7} \mathrm{COOAg}\right]+\mathrm{NaNO}_{3}$} Silver Oleate

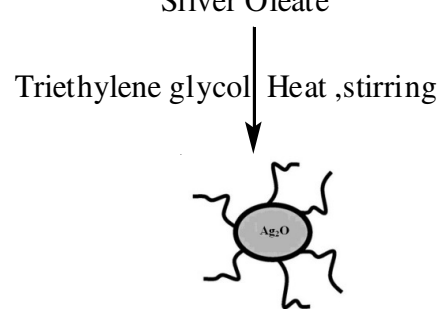

Fig. 1. Schematic presentation of formation of $\mathrm{Ag}_{2} \mathrm{O}$ nanoparticles

\section{RESULTS AND DISCUSSION}

Microscopic studies (SEM, TEM and EDX): The scanning electron micrograph for silver oxide as shown in Fig. 2(a), suggest that the morphology, although very uniform is not well defined. The EDX studies (Fig. 2b) clearly showed the formation of silver oxide.

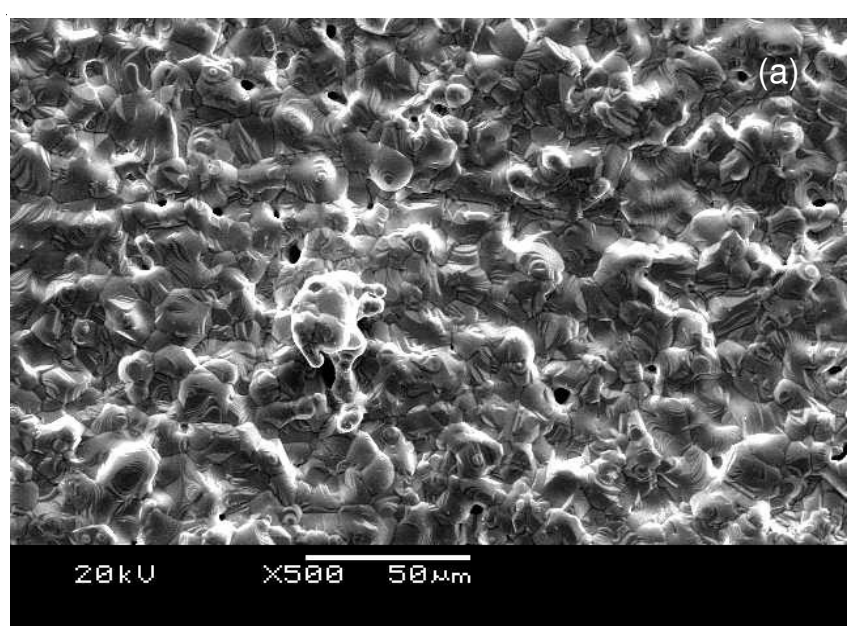

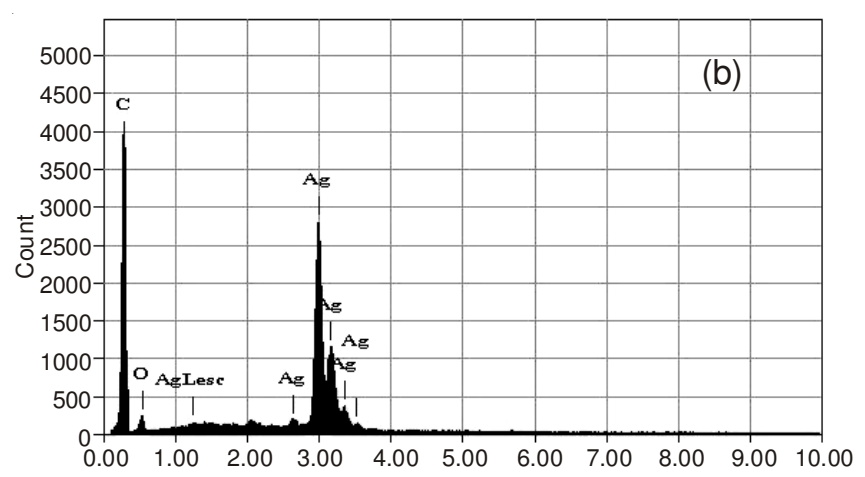

Fig. 2. (a) SEM micrograph and (b) EDX of $\mathrm{Ag}_{2} \mathrm{O}$ nanoparticles

The transmission electron microscopic studies (Fig. 3) reveal that the silver oxide particles are well dispersed and uniform sized spherical shape. The size of the particles is found to be in the range $2-10 \mathrm{~nm}$, with an average mean size of 5.44 $\pm 0.13 \mathrm{~nm}$ as shown in Fig. 4. This uniform size and shape can be attributed to the use of oleic acid as capping agent, which is reported in literature to play dual role, i.e. as an extractant and as a surface-capping agent that protects the outer surface of the newly formed particles thus avoiding the possibility of further growth ${ }^{18}$ and triethylene glycol as protective agent to stabilize the dispersive nanoparticles during the course of metal nanoparticle preparation.

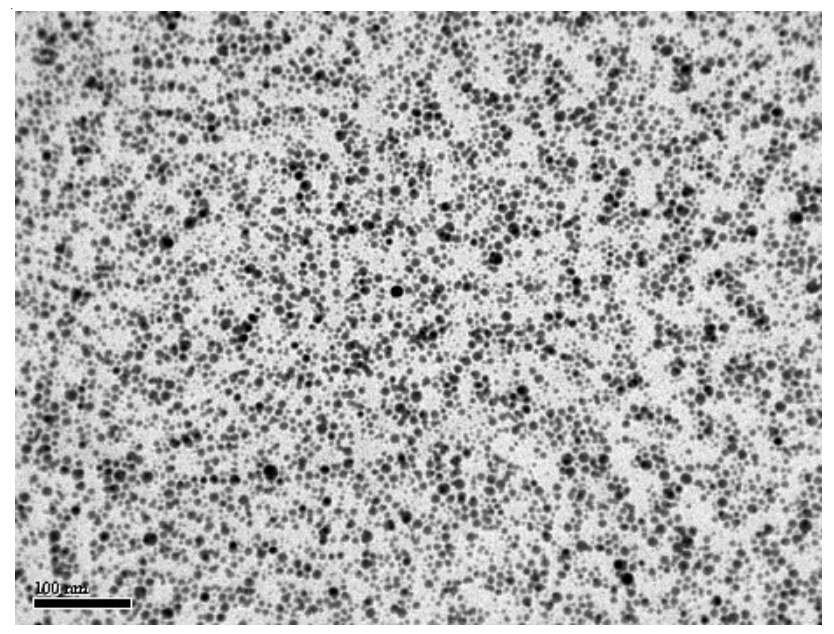

Fig. 3. TEM micrograph of silver oxide nanoparticles

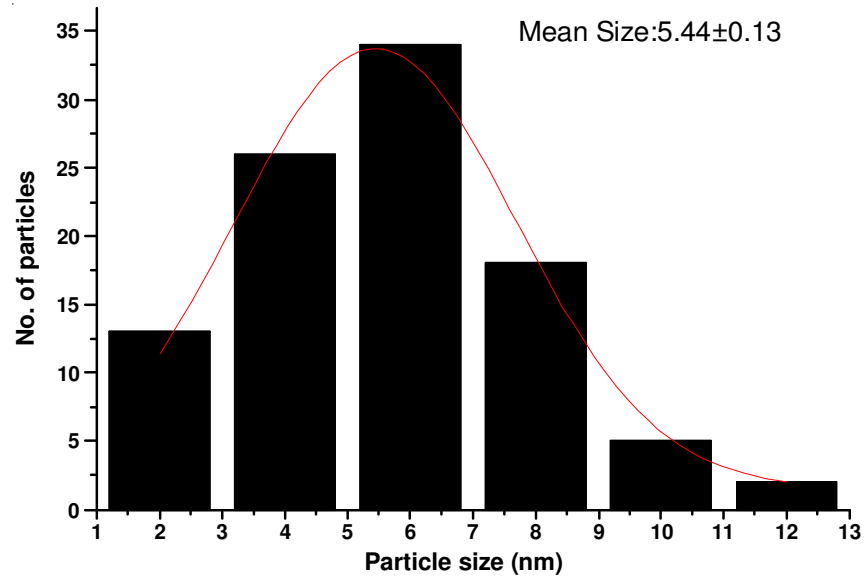

Fig. 4. Particle size distribution of silver oxide nanoparticles calculated from TEM 
The most common strategy is to protect the nanoparticles with protective agents that can absorb on or bind onto the nanoparticle surface, avoiding their agglomeration thus leading to a better dispersion of uniform sized particles ${ }^{19,20}$.

In an attempt to prepare $\mathrm{Ag}_{2} \mathrm{O}$ nanoparticles by decomposition of $\mathrm{AgCl}$ at high temperature in the presence of oxygen, silver chloride powder, prepared by silver nitrate precipitation with $\mathrm{HCl}$ was kept in an oven overnight at $650^{\circ} \mathrm{C}$.

The product was characterized by scanning electron microscopy, transmission electron microscopy and surface analysis (energy dispersive X-ray analysis: EDX).The SEM studies revealed the morphology as hexagonal particles. The scanning electron micrograph is depicted in Fig. 5a. The EDX Fig. 5b studies performed on the sample showed the stoichiometric presence of $\mathrm{AgCl}$ and no oxygen was observed in the sample, which clearly indicates that the $\mathrm{AgCl}$ was stable even at the temperature.
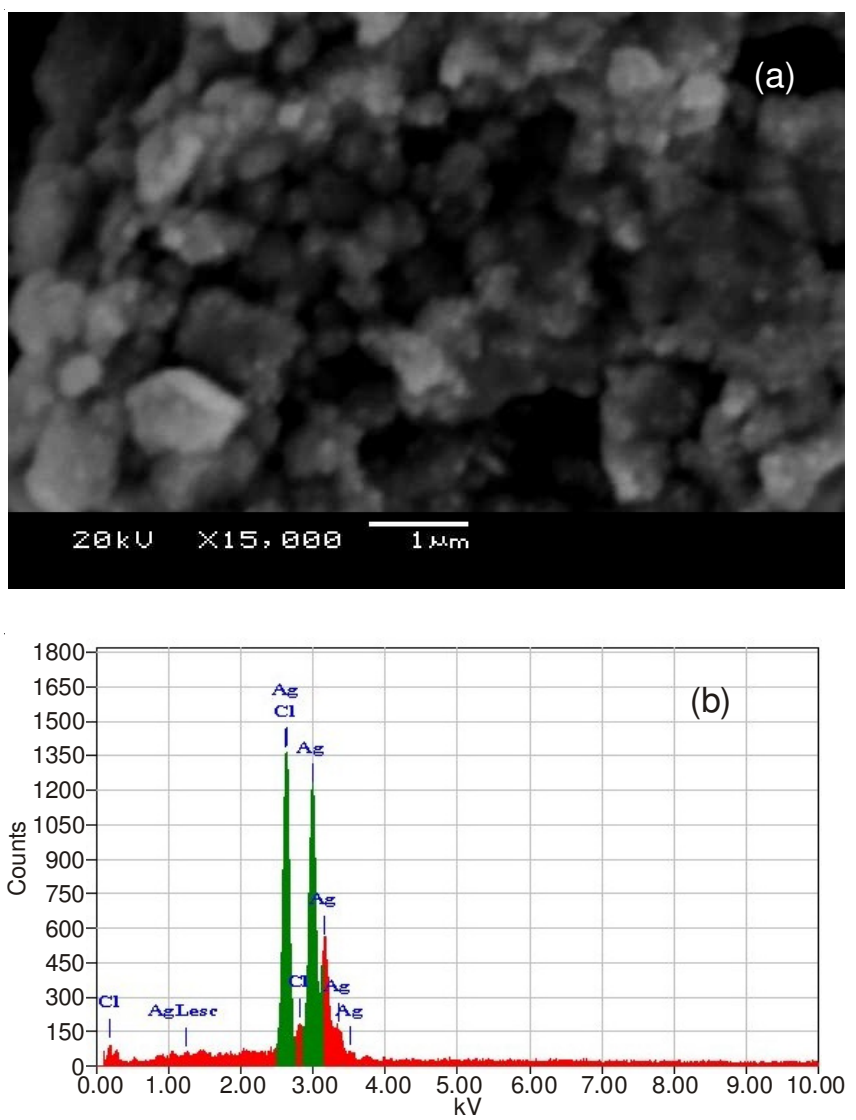

Fig. 5. (a) SEM micrograph and (b) EDX of $\mathrm{AgCl}$ nanoparticles

This EDX result indicated that the sample is purely $\mathrm{AgCl}$ and no $\mathrm{Ag}_{2} \mathrm{O}$ was formed even after thermal treatment in air at such high temperatures. This may be because $\mathrm{Ag}_{2} \mathrm{O}$ is less stable compared to $\mathrm{AgCl}$. $\mathrm{Ag}_{2} \mathrm{O}$ has a melting point of $300^{\circ} \mathrm{C}$ compared to $\mathrm{AgCl}$ which has a melting point of $455^{\circ} \mathrm{C}$.

Fig. 6 depicts the TEM image of $\mathrm{AgCl}$ nanoparticles. Transmission electron microscopy revealed the particles whichare dense and the size of these particles rangefrom $2 \mathrm{~nm}$ to $12 \mathrm{~nm}$. Closer look of these dense particles reveal significantly smaller nanoparticles. The sizes of these nanoparticles have been calculated and the distribution of these nanoparticles is shown in Fig. 7. This shows that the distribution is between
2-12 nm, with an average mean size of $4.16 \pm 0.24 \mathrm{~nm}$. $\mathrm{AgCl}$ nanoparticles have earlier been reported ${ }^{23}$, synthesized by using water soluble polyelectrolyte as capping agent. They also report the formation of nanoplates of $\mathrm{AgCl}$ with a polygonal edge of diameter $250-300 \mathrm{~nm}$.

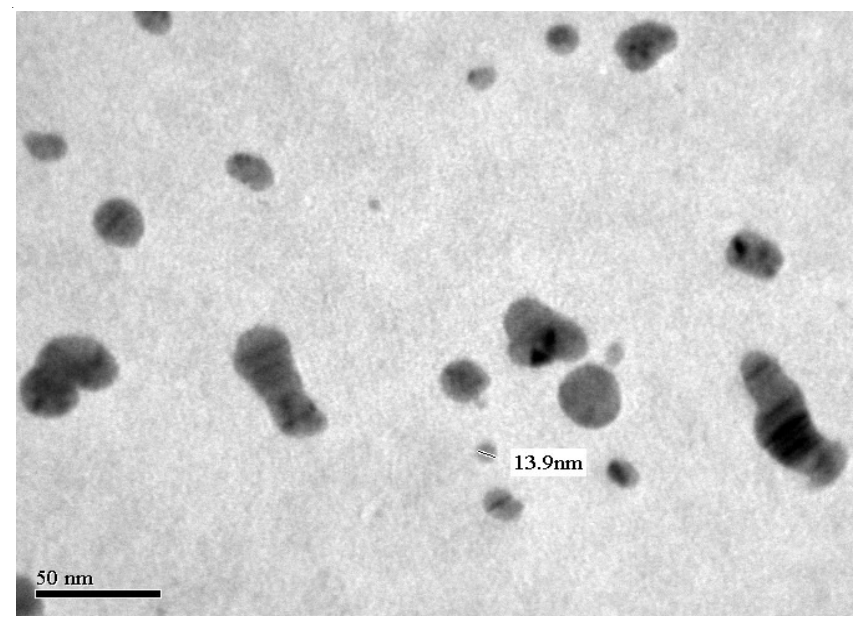

Fig. 6. TEM microgram of $\mathrm{AgCl}$ nanoparticles

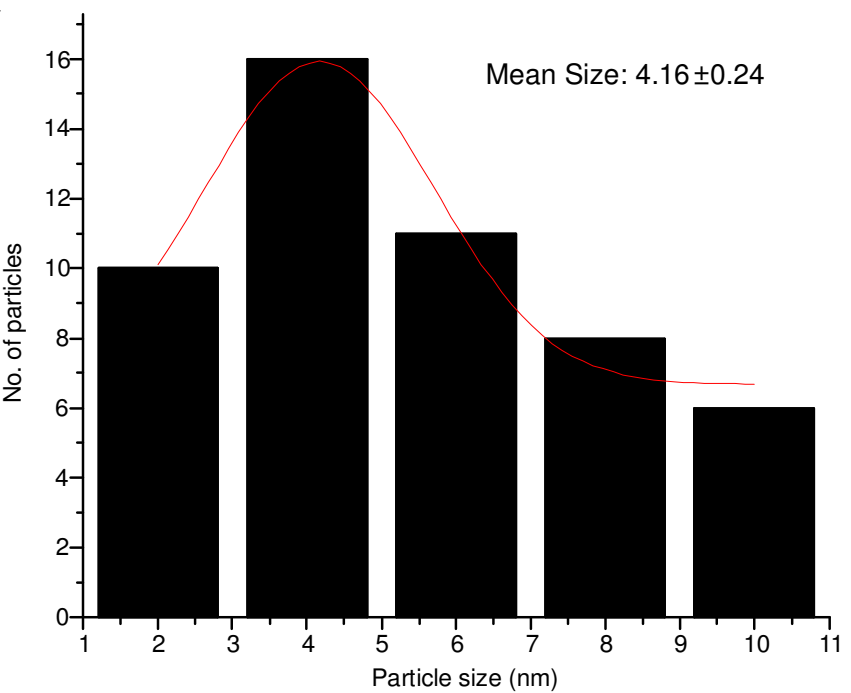

Fig. 7. Particle size distribution of $\mathrm{AgCl}$ nanoparticles calculated from TEM

Spectroscopic studies (XRD and FT-IR): The X-ray diffraction pattern (Fig. 8) of $\mathrm{Ag}_{2} \mathrm{O}$ nanoparticles showed sharp reflections corresponding to the face-centered cubic (FCC) structure which is in good agreement with the reported data of $\mathrm{Ag}_{2} \mathrm{O}^{21}$. The broadening of peaks indicates very small sizes of $\mathrm{Ag}$ crystallites. The crystallite size of the synthesized $\mathrm{Ag}_{2} \mathrm{O}$ nanoparticles was also calculated from the XRD spectrum using Debye-Scherrer's equation and the size was found to be in the range 11-12 $\mathrm{nm}$ and this value was further supported from the calculations made on theimage produced by TEM.

The XRD pattern of $\mathrm{AgCl}$ (Fig. 9) suggested that the structure is cubic shape, which is in good agreement with the reported data of $\mathrm{AgCl}^{22}$. The broadening of peaks indicates very small sizes of Ag crystallites. The crystallite size of the synthesized $\mathrm{AgCl}$ nanoparticles calculated by Debye-Scherrer's equation and the size was found to be in the range $11-14 \mathrm{~nm}$. The slight discrepancy in the particle size calculation by XRD and 
TEM measurements can be attributed to experimental error and also because XRD measurements are for the bulk sample.

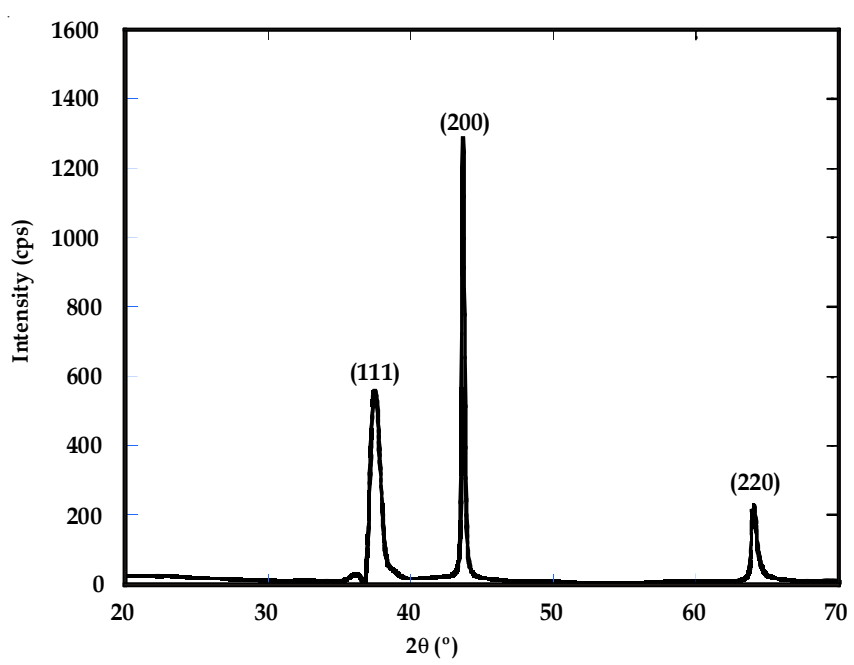

Fig. 8. X-Ray diffraction pattern of silver oxide nanoparticles

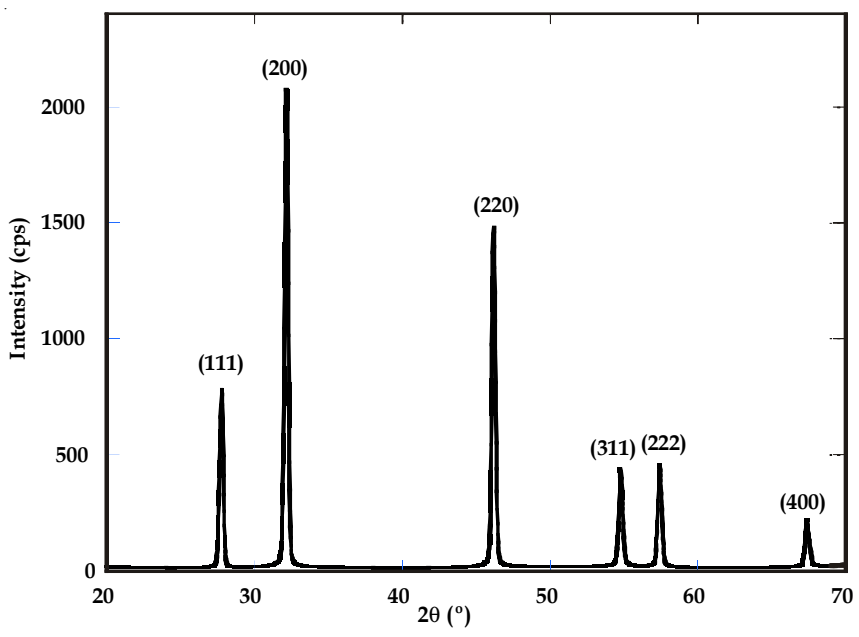

Fig. 9. X-Ray diffraction pattern of silver chloride nanoparticles

Fourier transform infrared spectroscopy spectrum of synthesized $\mathrm{Ag}_{2} \mathrm{O}$ nanoparticles (Fig. 10) displays the characteristic band attributed to lattice vibration of silver oxide at approximately $550 \mathrm{~cm}^{-1}$ which was absent in the FT-IR spectrum of synthesized $\mathrm{AgCl}$ nanoparticles (Fig. 11).

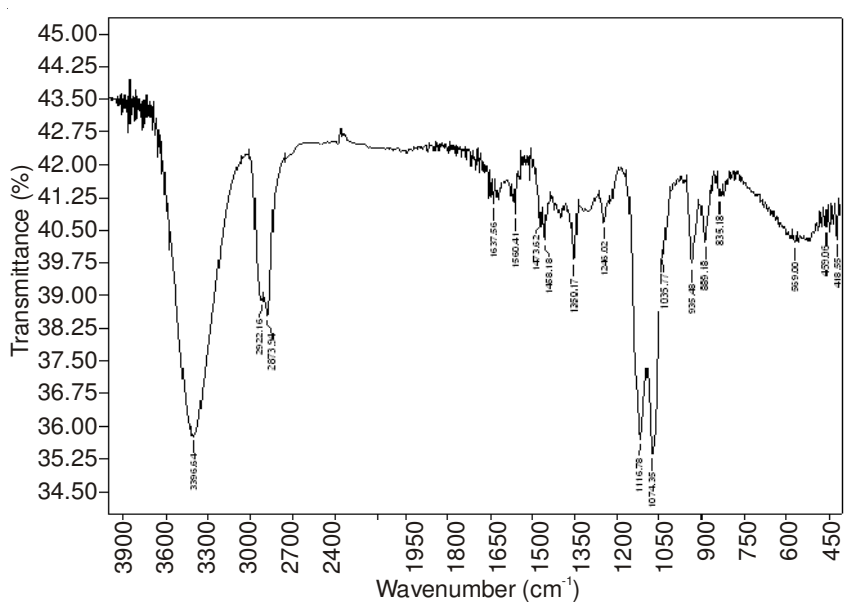

Fig. 10. FT-IR spectrum of synthesized silver oxide nanoparticles

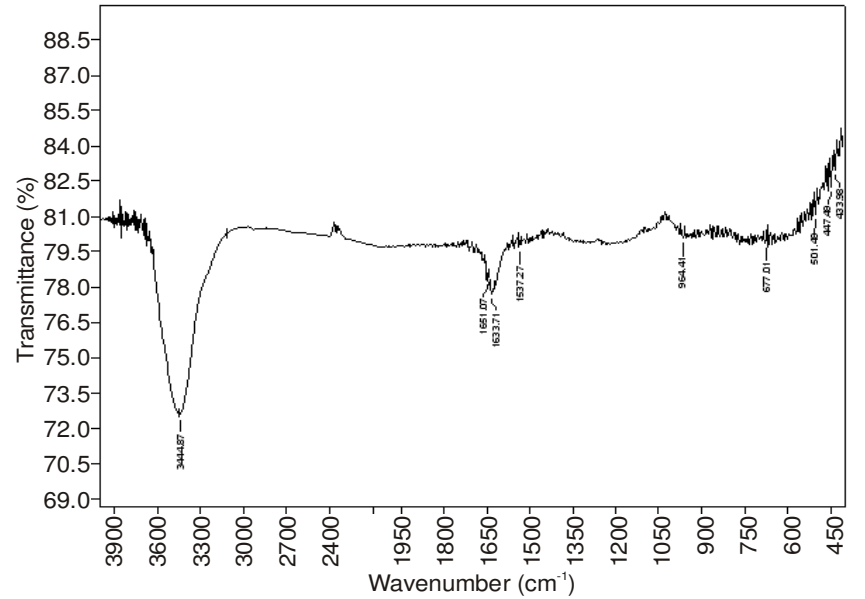

Fig. 11. FT-IR spectrum of synthesized silver chloride nanoparticles

Thermal studies: Thermogravimetric studies were carried out under nitrogen atmosphere with a heating rate of $10{ }^{\circ} \mathrm{C} /$ min, to check the stability of $\mathrm{AgCl}$ nanoparticles. These studies also clearly support the stability of $\mathrm{AgCl}$ nanoparticles to over $650{ }^{\circ} \mathrm{C}$. The polyelectrolyte capped $\mathrm{AgCl}$ nanoparticles were reported ${ }^{23}$ to be stable only up to the melting point of $\mathrm{AgCl}$ which is $455^{\circ} \mathrm{C}$. The nanoparticles in the present work are not only smaller in size (2-12 $\mathrm{nm})$ but also have a high thermal stability.

The TGA of $\mathrm{AgCl}$ nanoparticles synthesized is shown in Fig. 12. This indicates that there is no weight loss up to $650^{\circ} \mathrm{C}$ and even up to $800{ }^{\circ} \mathrm{C}$ the weight loss is around $12 \%$. For the total loss of chlorine in $\mathrm{AgCl}$ the weight loss should be $24.7 \%$. The lower weight loss indicates that even after $800{ }^{\circ} \mathrm{C}$ all the chlorine present in the $\mathrm{AgCl}$ is not lost. Further the stability of the $\mathrm{AgCl}$ nano particles up to $650^{\circ} \mathrm{C}$ clearly indicate that these $\mathrm{AgCl}$ nanoparticles act as molten salt or ionic liquids in the range of 455 to $650{ }^{\circ} \mathrm{C}$. We have earlier synthesized low temperature ionic liquids of gold and have established a method of showing ionic liquid window from thermogravimetric studies $^{24}$.

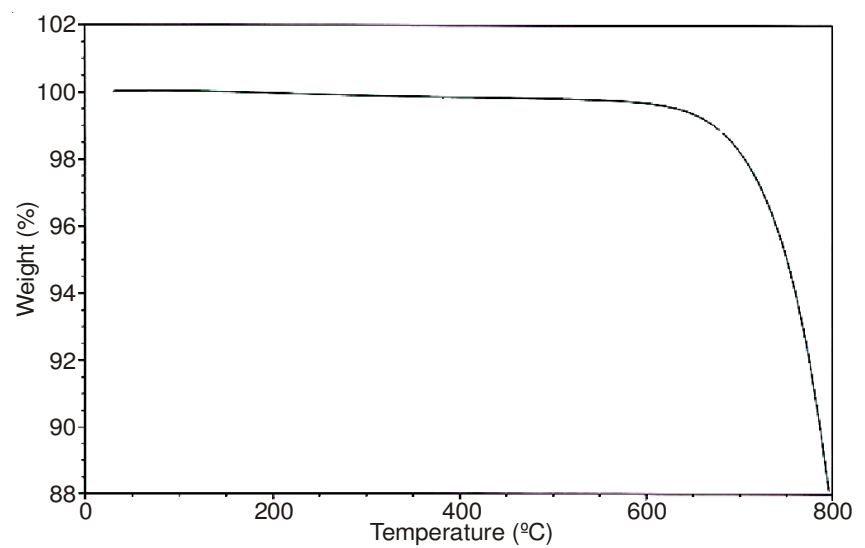

Fig. 12. Thermogravimetric analysis curve of silver chloride nanoparticles

The activities of $\mathrm{AgCl}$ in molten $\mathrm{MgCl}_{2}-\mathrm{KCl}(32.5: 67.5$ mole \%) and in molten $\mathrm{MgCl}_{2}-\mathrm{NaCl}-\mathrm{KCl}(50: 30: 20 \mathrm{~mol} \%)$ as solvent at $475^{\circ} \mathrm{C}$ have been reported earlier ${ }^{25}$. To our best of knowledge this is the first report of the behaviour of $\mathrm{AgCl}$ as molten salt in the range of 455 to $650{ }^{\circ} \mathrm{C}$. 
While the silver oxide particles do not exhibit such high thermal stability which can be confirmed by the TGA graph obtained. A major loss of weight at around $200{ }^{\circ} \mathrm{C}$ was observed, which is usually a trend observed with organic moieties, it suggests that the silver oxide particles are surrounded with the capping agent, which maintain the size and shape of nanoparticles synthesized (Fig. 13).

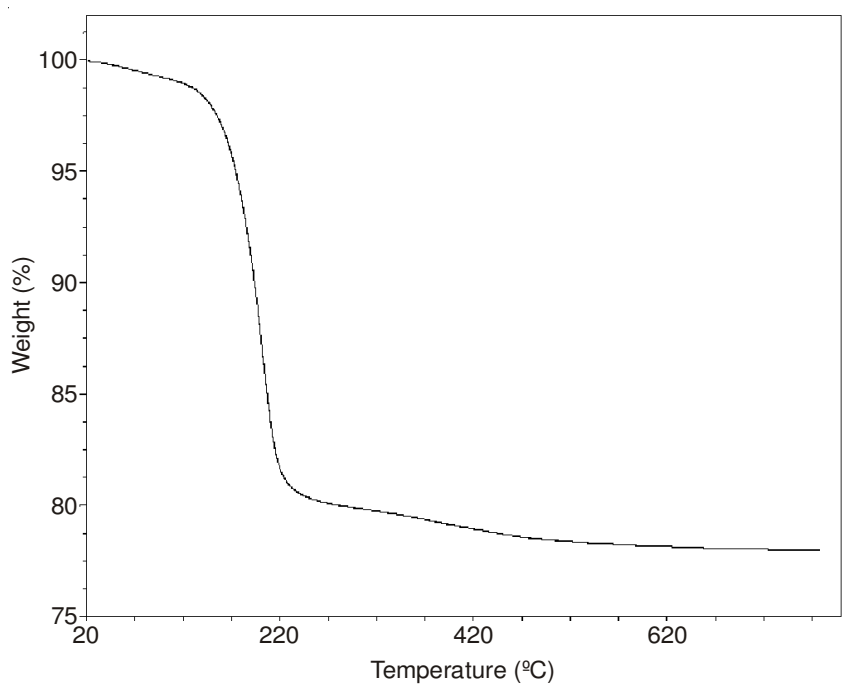

Fig. 13. Thermogravimetric analysis curve of silver oxide nanoparticles

The procedure reported here is straight forward and simple, while previous reports of $\mathrm{AgCl}$ nanoparticles were prepared by direct precipitation of silver ions with the surfactant counter ion in the water pools of microemulsions formed by dioctyldimethylammonium chloride in an organic $n$-decanol/ isooctane phase.

The size of the nanoparticles was affected by various factors such as surfactant and cosurfactant concentrations, of the mole ratio of water to surfactant, $\mathrm{R}$ and of the loading of silver nitrate were evaluated. Increasing the surfactant concentration at fixed values of $\mathrm{R}$ and moles of silver nitrate resulted in a higher dependency on the reverse micellar exchange dynamics and increased the particle size ${ }^{26}$. Furthermore these studies did not attempt to study the thermal stability of $\mathrm{AgCl}$ nanoparticles.

\section{Conclusion}

In summary, we herein report a simple facile and straight forward synthesis of $\mathrm{Ag}_{2} \mathrm{O}$ and thermally stable $\mathrm{AgCl}$ nanoparticles. The $\mathrm{AgCl}$ nanoparticles synthesized were found to be between 2-12 $\mathrm{nm}$ and thermally stable up to $650{ }^{\circ} \mathrm{C}$. These nanoparticles behave as ionic liquid in the region of 455 to $650{ }^{\circ} \mathrm{C}$. Such high thermal stability and ionic liquid properties may lead to new applications of these nanoparticles in catalysis and material chemistrywhereas, the $\operatorname{Ag}_{2} \mathrm{O}$ nanoparticles are not stable thermally but were found to be uniform and spherical in shape. Further studies are being carried out to find out the potential applications of the synthesized nanoparticles.

\section{REFERENCES}

1. Y.S. Tarahovsky, Y.A. Kim and G.R. Ivanitsky, Dokl. Biochem. Biophys., 422, 265 (2008).

2. M. Zhang, S. Fang, A.A. Zakhidov, S.B. Lee, A.E. Aliev, C.D. Williams, K.R. Atkinson and R.H. Baughman, Science, 309, 1215 (2005).

3. A.R. Mayer and J.E. Mark, Colloid Polym. Sci., 275, 333 (1997).

4. M.H. Pishbin, A.R. Mohammadi and M. Nasri, Fuel Cells (Weinheim, Germany), 7, 291 (2007).

5. J.H. Lee, S.K. Hong and W.B. Ko, Asian J. Chem., 23, 5447 (2011).

6. K.I. Shimizu, K. Sugino, K. Sawabe and A. Satsuma, Chem. Eur. J., 15, 2341 (2009).

7. J.M. Schierholz, L.J. Lucas, A. Rump and G. Pulverer, J. Hosp. Infect., 40, 257 (1998).

8. S.H. Shin, M.K. Ye, H.S. Kim and H.S. Kang, Int. J. Immunopharmacol., 7, 1813 (2007).

9. C. Baker, A. Pradhan, L. Pakstis, D.J. Pochan and S.I. Shah, J. Nanosci. Nanotechnol., 5, 244 (2005).

10. J. Chen, C.M. Han, X.W. Lin, Z.J. Tang and S.J. Su, Zhonghua Wai Ke Za Zhi, 44, 50 (2006).

11. S. Osamu, M. Motoyuki, S. Yuichi, N. Takashi, K. Yoshimori, T. Toshio, S. Masakazu and K. Toshiaki, Japanese Patent Feb. 1, 2007 JP 2007026897 Application Jul 15, 2005. JP 2005-207538.

12. C. Michael, US patent Feb 14, 2008 US 20080038630 A1 Application Mar 25, 2005 US 2005-90471.

13. A.I. Akimov and G.K. Savchuk, Inorg. Mater, 41, 542 (2005).

14. I. Tomoaki and A. Wakana, Japanese Patent May 19, 2005 JP 2005129407 A Application Oct 24, 2003 JP 2003-364886.

15. W. Xudong, W. Lei, Y. Yongzhe, Z. Liqing, C. Xing, W. Tao, L. Zhixia, X. Wei, M. Qianqiu, B. Xiaorong, S. Hisashi and F. Kennichi, Chinese patent May 20, 2009 CN 101435794 Application No.Dec 19, 2008CN 2008-10232735

16. C.N. Louis, K. Iyakutti and P. Malarvizhi, J. Phys. Condens. Mater, 16, 1577 (2004).

17. M. Yu, R. Skouta, L. Zhou, H.F. Jiang, X. Yao and C.J. Li, J. Org. Chem., 74, 3378 (2009).

18. P.K. Khanna, T.S. Kale, M. Shaikh, N.K. Rao and C.V.V. Satyanarayana, Mater. Chem. Phys., 110, 21 (2008).

19. M. Oliveira, D. Ugarte, D. Zanchet and A. Zarbin, J. Colloid Interf. Sci., 292, 429 (2005).

20. J. Bai, Y. Li, J. Du, S. Wang, J. Zheng, Q. Yang and X. Chen, Mater. Chem. Phys., 106, 412 (2007).

21. Y. Jinhu, Q. Limin, Z. Dongbai, M. Jiming and C. Humin, Cryst. Growth Design, 4, 1371 (2004).

22. M. Choi, K.H. Shin and J. Jang, J. Colloid Interf. Sci., 341, 83 (2010).

23. J.P. Tiwari and R.K. Chepuri, Solid State Ionics, 179, 299 (2008).

24. M. Hasan, I.V. Kozhevnikov, M.R. Siddiqui, A. Steiner and N. Winterton, Inorg. Chem., 38, 5637 (1999).

25. H.L. Jindal, Aust. J. Chem., 26, 57 (1973).

26. H. Maen, R. Eva and V. Juan, Langmuir, 19, 8467 (2003). 